Int. J. Dev. Biol. 50: 611-617 (2006)

doi: $10.1387 / \mathrm{ijdb} .052110 \mathrm{~cm}$

Original Article

\title{
The zic1 gene is an activator of Wnt signaling
}

\author{
CHRISTA S. MERZDORF" and HAZEL L. SIVE* \\ Whitehead Institute for Biomedical Research and Massachusetts Institute of Technology, Cambridge, USA
}

\begin{abstract}
The zic1 gene plays an important role in early patterning of the Xenopus neurectoderm. While Zic1 does not act as a neural inducer, it synergizes with the neural inducing factor Noggin to activate expression of posterior neural genes, including the midbrain/hindbrain boundary marker engrailed-2. Since the Drosophila homologue of zic1, odd-paired (opa), regulates expression of the wingless and engrailed genes and since Wnt proteins posteriorize neural tissue in Xenopus, we asked whether Xenopus Zic1 acted through the Wnt pathway. Using Wnt signaling inhibitors, we demonstrate that an active Wnt pathway is required for activation of en-2 expression by zic1. Consistent with this result, Zic1 induces expression of several wnt genes, including wnt1, wnt4 and wnt8b. wnt1 gene expression activates expression of engrailed in various organisms, including Xenopus, as demonstrated here. Together, our data suggest that zic1 is an upstream regulator of several wnt genes and that the regulatory relationships between opa, wingless and engrailed seen in Drosophila are also present in vertebrates.
\end{abstract}

KEY WORDS: zic, wingless, wnt, Xenopus, engrailed, neural

\section{Introduction}

Wnt signaling is involved in many developmental processes and despite the considerable understanding of this pathway, the upstream events that regulate wntgene expression are not well understood (Wodarz and Nusse, 1998, Logan and Nusse, 2004, Wang and Wynshaw-Boris, 2004, Ciani and Salinas, 2005). In Drosophila, the odd-paired (opa) gene is required for activation of wingless gene expression (Benedyk et al., 1994).

Vertebrate opa homologues are members of the zic gene family of zinc finger transcription factors (Kuo etal., 1998, Mizuseki et al., 1998, Nakata et al., 1998). zic genes have been implicated in patterning the dorsal neural tube, in neural crest development and in cerebellar development (Aruga, 2004). Do zic genes regulate Wnt signaling in vertebrates? The zic1gene (also called opland zicr-1) (Kuo et al., 1998, Mizuseki et al., 1998, Nakata et al., 1998) may be involved in regulating wntexpression. Throughout early development in Xenopus, zic1 and several wnt genes show extensive overlap in their expression patterns in the presumptive neurectoderm, in the dorsal neural tube, at the forebrain/midbrain boundary and at the midbrain/hindbrain boundary (McGrew et al., 1992, Wolda et al., 1993, Cui et al., 1995, Chang and Hemmati-Brivanlou, 1998, Kuo etal., 1998), suggesting there may be a regulatory connection between zic1 and wnt genes. Further, wnt genes are known to posteriorize neural tissue in animal cap (undifferentiated ectoderm) assays (McGrew et al., 1995, McGrew etal., 1997, Chang and Hemmati-Brivanlou, 1998, Domingos et al., 2001). This activity is shared by zic1 (Kuo et al., 1998). In particular, when the BMP inhibitor Noggin is expressed in animal caps from Xenopus, these animal caps express panneural genes and a subset of anterior neural genes (Lamb et al., 1993), while co-expression of Wnt proteins activates more posteriorly expressed genes (McGrew etal., 1995). Zic1 alone does not induce neural gene expression. Neither does Zic1 $\Delta \mathrm{C}$, a C-terminally truncated form of Zic1 that shows enhanced transcriptional activation activity compared to full length Zic1 (ziC1 $\Delta C=o p / \Delta C$, Kuo et al., 1998). However, like Wnt proteins, both Zic1 $\Delta \mathrm{C}$ and full length Zic1 synergize with Noggin to induce expression of posterior neural genes that are not activated by Noggin alone. One such gene is the midbrain/hindbrain boundary marker en-2(Kuo et al., 1998), which is a target of Wnt signaling (Danielian and McMahon, 1996, McGrew et al., 1999).

Since both zic1 and wntgenes are able to posteriorize neural tissue and because zic1 is a homologue of the Drosophila oddpaired (opa) gene that is involved in the regulation of wingless $(\mathrm{wg})$ and engrailed (en) expression (Benedyk et al., 1994), we asked whether zic1 acts through the Wnt pathway to induce en-2. Our

Abbreviations used in this paper: C-terminus, carboxy-terminus; opa, odd-paired gene; PCR, polymerase chain reaction; RT, reverse transcriptase.

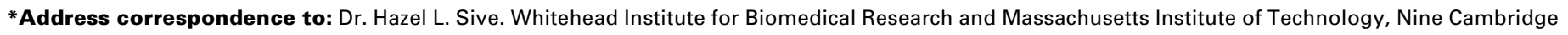
Center, Cambridge MA 02142, USA. Fax: +1-617-258-5578. e-mail: sive@wi.mit.edu
} 
data suggest that regulatory relationships between the opa, wg and engenes in Drosophila are conserved among the vertebrate homologues of these genes.

\section{Results}

\section{Zic1 induces expression of en-2 via the Wnt pathway}

zic1 and en-2 expression domains overlap in early neurula (stage 14) embryos (Kuo et al., 1998). We began this study by showing a similar overlap in $\mathrm{mid} / \mathrm{late}$ neurula (stage 17) embryos between the zic1 expression domain (Fig. 1A) and the expression domain of the en-2gene (Fig. 1B).

In order to investigate the regulatory relationships between zic1, en-2and wntgenes, we utilized animal cap assays. In vitro synthesized zic1 1 C and noggin RNAs were injected into 2-cell embryos, animal caps were isolated at late blastula (stage 9) and maintained in culture until control embryos reached early tailbud (stage 22), when they were harvested for RT-PCR analysis. Control experiments showed that animal caps injected with either $\beta$-globin or with zic1 $C$ alone did not show expression of either the pan-neural gene $N$-CAMor the anterior neural marker otx2 (Fig. 2; lanes 1 and 2). On the other hand, animal caps neuralized with Noggin showed induction of both N-CAM and otx2 expression (lane 3). In contrast, en-2 expression was induced when zic1 $C$ and noggin were co-expressed in animal caps (lane 4). These data are consistent with previous studies showing that inhibition of BMPs is required for the induction of en-2 by zic1 in animal cap explants (Kuo et al., 1998).

We next asked whether an active Wnt signaling pathway is required for the induction of $e n-2$ by zic1. We examined the

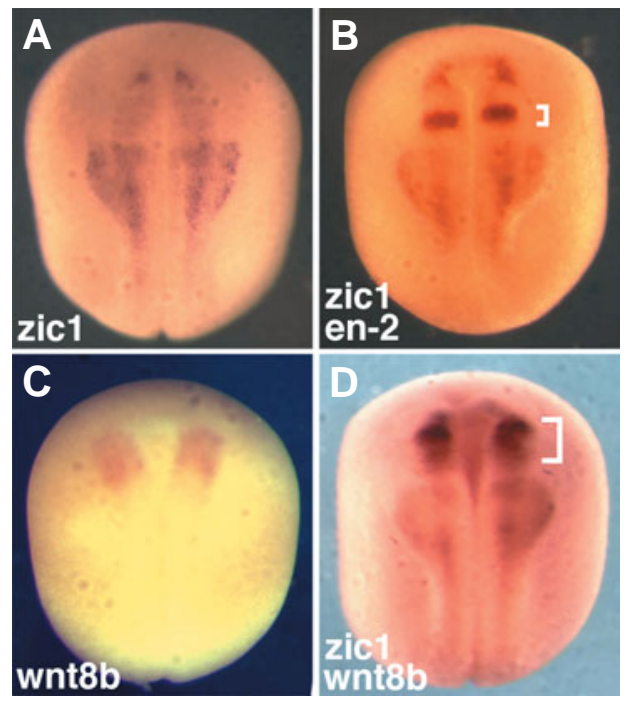

Fig. 1. The zic1 expression domain overlaps with those of both en2 and $\mathbf{w n t} 8 \boldsymbol{b}$. In situ hybridization of stage 17 neurula embryos. (A) zic1 expression domain. (B) Double in situ hybridization with zic1 and en-2 probes shows overlap between the two expression domains. The bracket indicates en-2 expression. (C) wnt8b expression domain in the midbrain. (D) Double in situ hybridization with zic1 and wnt8b probes indicates that their expression domains overlap. The bracket indicates wnt8b expression. necessity for Wnt signaling by using two different inhibitors of the canonical Wnt pathway. The first was a dominant interfering wnt8construct (dnWnt) (Hoppler etal., 1996). Co-expression of dnWntRNA in zic1 $\Delta C$-injected neuralized animal caps blocked induction of en-2 expression (Fig. 2, lane 5). The second inhibitor was GSK3(He et al., 1995), which promotes degradation of $\beta$-catenin, thus blocking the Wnt pathway. Co-expression of GSK3 RNA and ziC1AC in neuralized animal caps also inhibited induction of en-2 expression (lane 6). The same experiments were conducted with full length zic1, where activation of en-2expression was also abolished by co-expression of full length zic/plus noggin with either of the two Wnt pathway inhibitors (not shown). Thus, induction of en-2 expression by Zic1 requires an active Wnt pathway.

\section{Zic1 activates expression of a subset of wnt genes}

One interpretation of these results is that $z i c 1$ might regulate the expression of wnt genes. To examine this possibility, we expressed zic1 1 C or full length zic 1 with or without noggin and assayed wnt gene expression in animal caps (Fig. 3). Animal caps were examined by RT-PCR analysis for expression of the wnt1, wnt3a, wnt4, wnt5a, wnt5c, wnt7b, wnt8, wnt8b and $w n t 11$ genes. Animal caps taken from embryos injected with RNAs for either $\beta$-globin, noggin, zic1 $\Delta C$, or full length zic1 (Fig. $3 A$, lanes 1-3 and 5) showed low or undetectable expression levels of $w n t 1, w n t 4$ and wnt8b. In contrast, caps removed from embryos co-injected with zic1 $C$ C plus noggin showed strong induction of wnt $1, w n t 4$ and $w n t 8 b$ expression (lane 4) relative to control caps. Expression of full length zic1 in combination with noggin activated lower levels of wnt 1 and wnt8b expression than did zic $1 \Delta C$ and did not induce significant expression of wnt4 (lane 6). In the absence of noggin, zic1 $C$, but not full length zic1, activated appreciable levels of wnt 1 expression (lanes 3 and 5).

In the same assay, expression of $w n t 8, w n t 3 a$ and $w n t 7 b$ was strong or detectable in animal caps that were not expressing Noggin (Fig. 3B, C; lanes 1, 3 and 5) and weak or absent in caps expressing Noggin (lanes 2, 4 and 6). Although Zic1 $\Delta \mathrm{C}$ activated expression of wnt8 (lane 3), the relevance of this is unclear. When ectopically expressed in dorsal mesoderm during gastrulation, wnt8 causes a loss of anterior structures (Christian and Moon, 1993), although the expression of en-2is unchanged (Fredieu etal., 1997). Thus, the induction of wnt8by zic $1 \Delta C$ is probably not relevant to the induction of $e n-2$. What is the relevance of high $w n t 7 b$ and $w n t 3 a$ expression in control or $\beta$-globin-expressing animal caps (Fig. 3C, lane 1) and lack of expression in neuralized caps (lanes $2,4,6)$ ? Since $w n t 7 b$ is expressed not only in the neural plate but also in the epidermis (Chang and Hemmati-Brivanlou, 1998), Noggin may inhibit expression of the epidermal component of $w n t 7 b$ expression in our assays. However, because wnt3ais expressed in the dorsal neural tube in an extensively overlapping domain with zic1 (McGrew et al., 1997, Kuo et al., 1998) and wnt3a is known to induce en-2 expression in neuralized animal caps (McGrew et al., 1995), we had not expected downregulation of wnt3a by Noggin.

We also tested induction of wnt5a, wnt5c and wnt11 expression in this assay, however none of these genes showed activation of expression by the $z i c 1 \Delta C / z i C 1+$ noggin RNA com- 


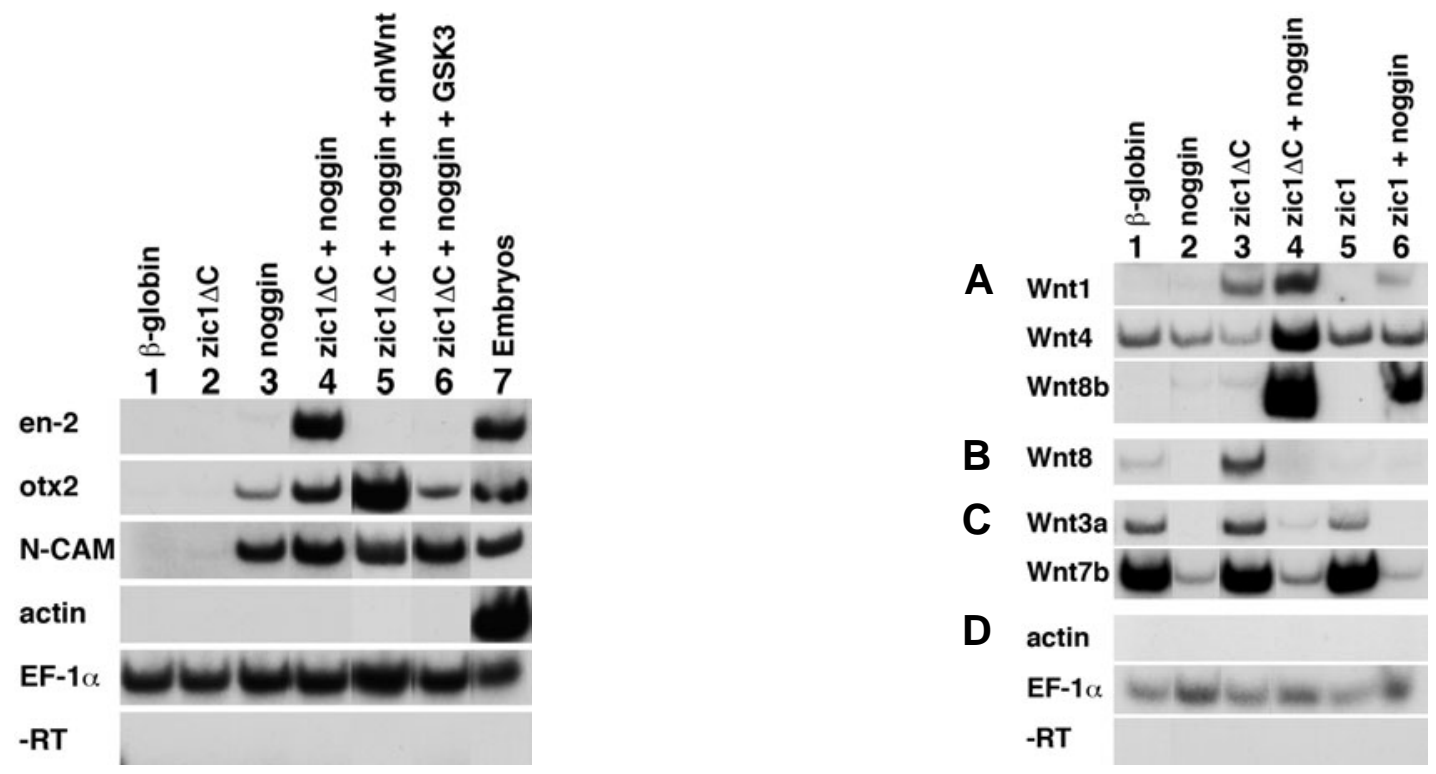

Fig. 2 (Left). Zic1 acts through the Wnt pathway to activate en-2. Both cells of 2-cell stage embryos were injected with the in vitro synthesized RNAs listed along the top. A C-terminal truncation of the zic1 coding sequence was used (zic1 $1 \mathrm{C}$ ). Animal caps were isolated at stage 9 and cultured until sibling embryos reached stage 22. Total RNA was isolated and subjected to RT-PCR analysis with the primers shown on the left. (Lanes 1,2), $\beta$-globin or zic $1 \Delta \mathrm{C}$ injected animal caps did not show expression of neural markers. (Lane 3) Noggin mRNA induced the anterior neural marker otx2 and the general neural marker N-CAM. (Lane 4) Co-injected zic1 $\Delta \mathrm{C}$ plus noggin induced expression of the midbrain/hindbrain boundary marker en2. Induction of en-2 expression is inhibited by dnWnt (lane 5) or GSK3 (lane 6), which are inhibitors of the Wnt pathway. This demonstrates that Zic1 requires an active Wnt pathway to induce en-2 expression. N-CAM and otx2 were expressed in all samples that received noggin (lanes 3-6). (Lane 7) Whole embryos at stage 22 served as positive control. Muscle actin controlled for mesodermal contamination, EF- $1 \alpha$ served as loading control and -RT samples controlled for DNA contamination. After culture to the equivalent of stage 22, animal caps expressing $\beta$-globin and zic 1 constructs were always completely round. Noggin-expressing animal caps were occasionally elongated, but the amount of noggin used was low enough that most explants were round. Co-injection of dnWnt or GSK3 RNA did not influence the shape of the animal caps beyond the effects of noggin. Injections were as follows: $200 \mathrm{pg} \beta$-globin, $200 \mathrm{pg}$ zic1 $\Delta \mathrm{C}, 5 \mathrm{pg}$ noggin, $150 \mathrm{pg}$ dnWnt8, 80 pg GSK3.

Fig. 3 (Right). Zic1 induces wnt expression. Embryos were injected into both blastomeres at the 2-cell stage with the indicated RNAs. zic1 $\triangle \mathrm{C}$ was tested in addition to full length zic1. Animal caps were isolated at stage 9 and cultured until sibling embryos reached stage 22. Total RNA was isolated and subjected to RT-PCR analysis with the primers shown on the left. (Lane 1) $\beta$-globin injected animal caps. (Lane 2) Noggin-injected. (Lane 3) zic1 $\Delta C$ injected. (Lane 4) zic1 $\Delta \mathrm{C}$ plus noggin-injected. (Lane 5) Full length zic1-injected. (Lane 6) Full length zic1 plus noggin-injected. (A) wnt1, wnt4 and wnt8b expression was induced by zic $1 \Delta \mathrm{C}$ plus noggin (lane 4). zic1 $1 \Delta \mathrm{C}$ alone induced wnt1 expression (lane 3), while full length zic1 plus noggin did not induce wnt4 expression (lane 6). (B) zic1 $\Delta \mathrm{C}$ induced wnt8 expression (lane 3). (C) wnt3a and wnt7b were expressed in $\beta$-globin, zic1 $\Delta \mathrm{C}$ and zic1injected animal caps (lanes 1, 3 and 5), but not in samples that had been co-injected with noggin (lanes 2, 4 and 6). (D) Muscle actin controlled for mesodermal contamination, EF-1 $\alpha$ served as loading control and-RT samples controlled for DNA contamination. Injections were as follows: 200 pg $\beta$-globin, $200 \mathrm{pg}$ zic1 $\Delta \mathrm{C}, 200 \mathrm{pg}$ zic1, $5 \mathrm{pg}$ noggin.

binations (data not shown). In sum, these assays showed selective activation of whtgene expression by combinations of activated or full length Zic1 plus Noggin.

\section{Expansion of the wnt8b expression domain by Zic1 in a whole embryo assay}

The strong induction of $w n t 8 b$ expression in animal caps coexpressing zic1 $1 \Delta / z i c 1+n o g g i n R N A s$ prompted us to investigate the ability of zic1 to induce wnt8b expression in whole embryos. First, we established that $w n t 8 b$ is expressed in the midbrain during neurula stages (Fig. 1C) and overlaps with the zic1 expression domain (Fig. 1D). Subsequently, zic1 $\Delta C$ or full length zic1 RNAs were co-injected with lacZ tracer RNA into albino embryos. In situ hybridization showed that the region of the embryo expressing $w n t 8 b$ was expanded by expression of $z i c 1 \Delta C$ (Fig. 4A) and to a lesser degree by expression of full length zic1 (Fig. 4B). Since the in situ assay is not quantitative and the responding tissue different in the animal cap and whole embryo assays, it is not clear whether the observed expansion is equivalent in the whole embryo and animal cap assays.

Importantly, the region in which wnt8b expression was expanded was contiguous with the endogenous wnt8b expression domain. Thus, whole embryos must contain factors that regulate where wnt8b expression can be modulated and zic 1 expression cannot be solely responsible for this modulation. Nonetheless, this result indicates that the animal cap assay accurately indicated the responsiveness of the embryo to zic1.

\section{Regulatory relationships between wnt1 and en-2 are con- served in Xenopus}

The $w n t 1$ and en-2 expression domains overlap at the Xenopus midbrain/hindbrain boundary (Li et al., 2006). Although regulatory connections between the wnt 1 gene and $e n-2$ have been shown in various organisms (McMahon et al., 1992, Sugiyama et 

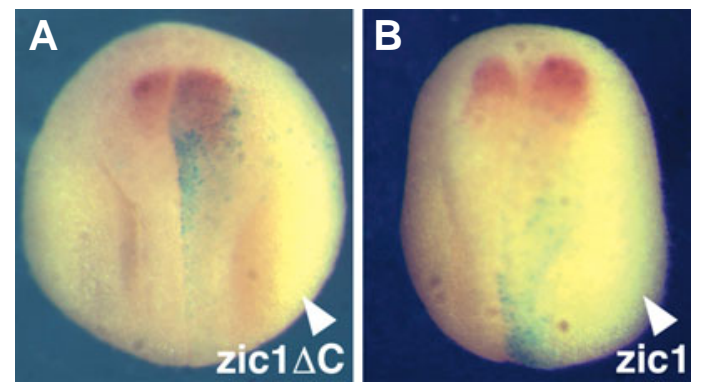

Fig. 4. Zic1 induces ectopic wnt8b expression. One cell of 2-cell albino embryos was injected with (A) 100 pg zic1 1 C RNA or with (B) 100 pg full length zic 1 RNA together with 25 pg lacZ RNA as tracer. In situ hybridization with wnt8b probe at neurula stage 18 showed that zic $1 \Delta \mathrm{C}$ and full length zic1 upregulate wnt8b expression on the injected (arrowheads) side.

al., 1998), this has not been as fully explored in Xenopus. We therefore tested Wnt 1 for its ability to induce en-2expression and found that Wnt1 induces robust en-2 expression in neuralized animal caps (Fig. 5, lane 3). At the same time, we confirmed that Wnt3a induces en-2 expression in neuralized animal caps (lane 4) (McGrew et al., 1995) and showed that Wnt8 induces en-2 expression (lane 5). In contrast, Wnt8b did not induce en-2 expression (lane 6) and Chang and Hemmati-Brivanlou (1997) showed previously that $\mathrm{Wnt} 7 \mathrm{~b}$ does not induce en-2in neuralized animal caps. This confirms that a regulatory pathway exists between the wnt and en-2 genes in Xenopus (McGrew et al., 1995, McGrew et al., 1999) and demonstrates that only a subset of Wnt proteins can activate en-2 expression.

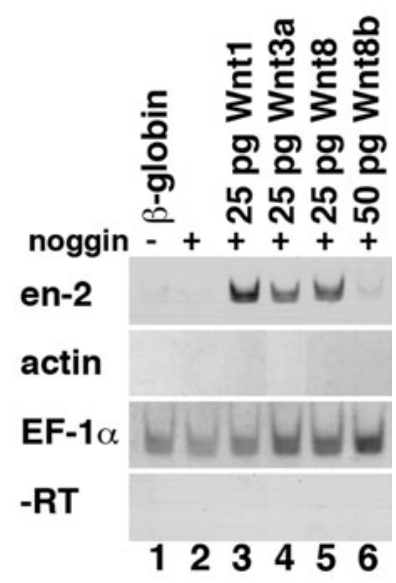

Fig. 5. Wnt1, Wnt3a and Wnt8 induce en-2 expression. Embryos were injected at the 2-cell stage into both cells with the sense RNAs listed along the top. Animal caps were isolated at stage 9 and cultured to the equivalent of stage 22. RT-PCR analysis was performed with the primers shown on the left. (Lanes 1,2) $\beta$-globin or noggin injected animal caps did not express en-2. (Lanes 3-5) 25 pg wnt1, 25 pg wnt3a and 25 pg wnt8 RNA induced en-2 expression. (Lane 6) $50 \mathrm{pg}$ wnt8b failed to induce en2 expression. All wnt RNAs were co-injected with 3 pg noggin RNA. The shape of the animal caps was round in all cases since very low levels of noggin and wnt RNAs were used. Muscle actin controlled for mesodermal contamination, EF-1 $\alpha$ served as loading control and -RT samples control for DNA contamination.
Having established in the explant assays that zic 1 forms a regulatory pathway with the wnt 1 and $e n-2$ genes, we asked whether Zic1 is able to induce ectopic $w n t 1$ and en-2 expression in whole embryos. Misexpression of Zic1 $\Delta \mathrm{C}$ in whole embryos resulted in an increase in the intensity of en-2staining, as assayed by in situhybridization, that was particularly evident in late neurula (stage 19) and older embryos (Fig. 6A). This increase in en-2 expression was limited to the normal en-2 expression domain, suggesting that other factors restrict the en-2expression domain. Expression of a dominant interfering form of zic1 (dnzich) strongly reduced expression of en-2(Fig. 6B) and wnt (Fig. 6C) in whole embryos, suggesting that Zic1 is necessary but not sufficient for the activation of $w n t 1$ and en-2 expression.

\section{Discussion}

We show that Zic1 requires an active Wnt pathway to induce expression of the en-2 gene in neuralized Xenopus ectodermal explants. This relationship is conserved in Drosophila, where opa is required for expression of the wgand engenes (Benedyk et al., 1994).

The ability of zic1 to induce neural genes in animal cap explants is dependent on the inhibition of BMP signaling to give the explants neural character (Kuo et al., 1998). In whole embryos, BMP antagonists secreted from the organizer, such as Noggin and Chordin, sequester BMP proteins and therefore allow dorsal determination and formation of neural tissues (Sasai and De Robertis, 1997, Munoz-Sanjuan and Brivanlou, 2002). Indeed, zic1, which is among the first molecular indicators of neural fate determination, is expressed in direct response to interruption of BMP signaling (Tropepe et al., 2006).

In animal caps, Zic1 acts through the Wnt pathway to activate en-2 expression and we found that the expression of three wnt genes ( $w n t 1, w n t 4$ and $w n t 8 b)$ is activated by Zic $1 \Delta \mathrm{C}$ in neuralized ectodermal explants. This suggests that Zic 1 interfaces with $w n t$ gene function by activating $w n t g e n e$ expression. The expression domains of these three wntgenes overlap with that of zic 1 during early embryonic stages. During gastrula stages, zic 1 expression overlaps with wht4 expression in the dorsal ectoderm (McGrew et al., 1992). During neurula stages, zic1 expression becomes restricted to the lateral edges of the neural plate and subsequently to the dorsal neural tube (Kuo et al., 1998), where its expression overlaps with that of wnt1 and wnt4 (McGrew et al., 1992, Wolda et al., 1993). Further, zic1 expression extends to the forebrain/ midbrain boundary, where the zic 1 and wnt8b expression domains overlap in the midbrain during neurula stages (this study) and at the forebrain/midbrain boundary during tailbud stages (Cui et al., 1995). At the midbrain/hindbrain boundary, zic1expression overlaps with expression of $w n t 1$ and $e n-2$ (Brivanlou and Harland, 1989, Wolda et al., 1993, Chang and Hemmati-Brivanlou, 1998, Kuo et al., 1998, Li et al., 2006).

Three consensus binding sites for LEF/TCF are present in the Xenopus en-2 promoter (McGrew et al., 1999), suggesting that the en-2gene is a direct target of canonical Wnt signaling. In the animal cap system, wnt1, wnt3aand wnt8, but not wnt8bor wnt7b, activated en-2 expression in neuralized animal caps (this study, McGrew et al., 1995, Chang and Hemmati-Brivanlou, 1998). Based on these considerations and on spatial expression patterns, $w n t 1$ is the most likely candidate through which zic 1 acts to 

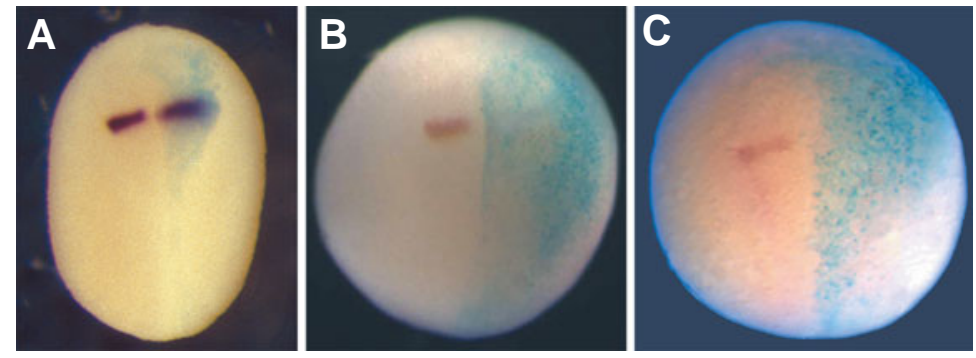

Fig. 6. Zic1 is required for en-2 induction. (A) One cell of 2-cell albino embryos was injected with $100 \mathrm{pg}$ zic $1 \Delta \mathrm{C}$ RNA, resulting in an increase of en2 expression levels within the en-2 expression domain. Embryos injected with $100 \mathrm{pg}$ of a dominant interfering zic1 construct (dnzic1) showed very significant decrease (B) in en-2 expression and $\mathbf{( C )}$ in wnt1 expression. All embryos were co-injected with $25 \mathrm{pg}$ lacZ RNA as tracer and the injected sides are shown on the right.

activate expression of en-2in Xenopus. This would be consistent with findings in mice, chick, Xenopus (this study) and Drosophila that connect wnt 1 activity with activation of engrailedexpression (DiNardo et al., 1988, Martinez Arias et al., 1988, Bally-Cuif et al., 1992, McMahon et al., 1992, Danielian and McMahon, 1996, Sugiyama et al., 1998).

Our data using dominant interfering constructs suggest that Zic1 is necessary for activation of wnt1 and en-2 expression. However, although Zic1 causes an increase in en-2 expression levels within its normal expression domain, ectopic Zic1 expression is not sufficient to induce ectopic en-2 expression. Thus, other factors must be required for induction of en-2 expression and helps explain why zic1, which is broadly expressed, can activate the expression of genes that are expressed in very restricted domains. We note that expression of other zic genes overlaps temporally and spatially with that of zic1 (Nakata et al., 1997, Nakata et al., 1998, Nakata et al., 2000). Our data do not distinguish whether other genes also act or synergize with Zic1 to activate wht and en-2 expression.

Genetic studies reveal a similar situation in Drosophila. Although loss of opafunction gives rise to pair-rule defects in body pattern, opa is different from all other pair-rule genes in that it is expressed in a broad, unsegmented domain rather than in a segmented fashion. opais required for the proper level and timing

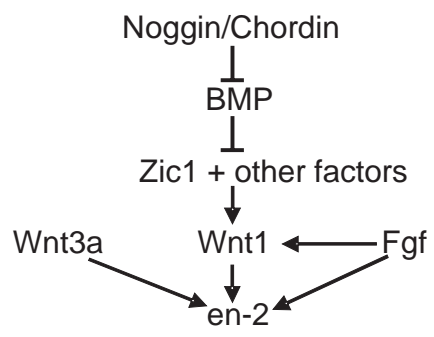

Fig. 7. Model of en-2 induction by Zic1. zic1 expression is activated after inhibition of BMP signaling by Noggin or Chordin. Zic1 and possibly other Zic proteins synergize with other factors to activate expression of wnt1 and other wnt genes. Wnt proteins activate expression of en-2. Wnt3a may act via a Zic1-independent pathway. An alternate pathway, by which en-2 expression is activated, may involve Fgf8 signaling. The activation events indicated by arrows need not necessarily be direct. of $w g$ and enexpression but not for correct positioning of the expression domains of $w g$ and en (Ingham et al., 1988, Benedyk etal., 1994). Similarly, zic 1is expressed in a much broader domain than wnt1 or en-2 (Kuo et al., 1998). Perhaps, analogous to opa activity in Drosophila, zic1 may act to regulate the timing (and possibly the maintenance and/or level) of wnt1 and en-2 expression but not the position of their respective expression domains.

In Drosophila, the genes $f t z$, prd and/or eve may positively regulate the position of en expression (Howard and Ingham, 1986, DiNardo and O'Farrell, 1987) and the runt gene may do so negatively in areas where $f t z$ is not present (Kania et al., 1990, Swantek and Gergen, 2004). Expression of $e n-2$ in vertebrates may also require further regulatory influences. For example, two pax binding sites are required for the expression of a mouse En-2 transgene (Song et al., 1996) and pax2 expression begins before engrailed expression at the midbrain/hindbrain boundary in $\mathrm{Xe}$ nopus (Heller and Brandli, 1997).

As reflected in our model (Fig. 7), the data indicate that Zic1 induces en-2via activation of Wnt1 signaling. Alternatively, there is evidence that Wnt signaling may induce $e n-2$ by an indirect mechanism that is dependent upon FGF signaling (Domingos et al., 2001). Expression of an FGF receptor in neuralized ectoderm results in the upregulation of en-2and wnt1expression (Umbhauer et al., 2000). Thus, Zic1 may induce en-2 by activating wnt1, which activates an FGF family member, which in turn activates en-2expression. Consistently, Zic1 appears to be able to induce fgfo (Li and Merzdorf, unpublished results), whose expression domain overlaps with the zic1, wnt1 and en-2 expression domains in Xenopus (Wolda et al., 1993, Kuo et al., 1998, Glavic et al., 2002). McGrew et al. (1997) find that Fgf induces en-2in the presence of Wnt pathway inhibitors and Lee et al. (1997) show that wnt1 regulates en-2 expression via the Fgf pathway in mouse. Thus, there may be two pathways of en-2 induction by wnt1, one direct via $\angle E F / T C F$ sites in the en-2promoter and one indirect via FGF signaling. It will be important to determine whether the initiation and the maintenance of en-2 expression rely on different parts of the pathway, as may be the case in mouse and in Drosophila.

In conclusion, we have shown that regulatory connections described for Drosophila opa are conserved in Xenopus. As in Drosophila, Zic1 may be responsible for the level and timing of en2 expression, rather than for its positioning. Further, the mechanisms underlying Zic1 activities may include activation of the expression of several wnt genes.

\section{Materials and Methods}

\section{Growth, microinjection, dissection and culture of embryos and explants}

Xenopus laevis eggs were collected, fertilized and cultured as in (Sive et al., 1989). Embryos were staged according to (Nieuwkoop and Faber, 1967). Microinjection techniques were as described (Kolm and Sive, 1995). For animal cap explant assays, both cells of 2-cell embryos were injected with a total of $100-200 \mathrm{pg} \beta$-globin RNA, $200 \mathrm{pg}$ zic1 or zic $\Delta C$ RNA (=op/ $\Delta C$ ) (Kuo et al., 1998); and 3-5 pg noggin RNA in various combinations. Further, 150 pg dnWnt8, 80 pg GSK3, 25 pg wnt1, 25 pg $w n t 3 a, 25 \mathrm{pg} w n t 8$ and $50 \mathrm{pg} w n t 8 b$ RNAs were injected in combination with other RNAs as detailed in the figure legends. For animal caps, late 
blastula (stage 9) animal hemisphere ectoderm was isolated and incubated in 0.5x MBS until sibling embryos reached stage 22 .

\section{In vitro transcription}

For production of in vitro transcribed RNAs, the entire coding sequence of zic1 was cloned into pCS2+ by PCR (several C-terminal amino acids were absent in the original zic1 construct used in Kuo et al., 1998). Capped sense RNAs for microinjection were synthesized for zic1 and zic1 1 CRNA in pCS2+ by SP6 transcription of a Narl/Narl fragment. The dominant interfering zic1 (dnzic1) construct was made by PCR amplification of the zinc finger domain and $\mathrm{C}$-terminus of the zic1 coding region. This PCR product was cloned into the Nco1 and Xba1 sites of the pCS2+ATG plasmid. The pCS2+ATG was made by inserting a Kozak sequence between the BamH1 and EcoR1 sites of the pCS2+ vector. The coding sequence of wnt 1 was cloned into pCS2+ by PCR. wht 1 sense RNA was synthesized by SP6 transcription from the Notl-digested pCS2+ wnt 1 plasmid. Other sense RNAs were synthesized as published: noggin (Smith and Harland, 1992), $\beta$-globin (Krieg and Melton, 1984), wnt3a(Wolda etal., 1993), wnt8(Christian et al., 1991), wnt8b(Cui et al., 1995), dnWnt8 (Hoppler et al., 1996), GSK3 (He et al., 1995) and lacZ (Turner and Weintraub, 1994).

Antisense probes for in situ hybridization were transcribed as previously described: zic1 (Kuo et al., 1998), en-2 (Hemmati-Brivanlou and Harland, 1989), wnt1 and wnt3a(Wolda etal., 1993). Since the antisense probe synthesized from the wnt 86 construct, kindly provided by Jan Christian, does not hybridize to neurula embryos, we synthesized wnt8b antisense RNA probe using T7 polymerase on a PCR product as template. The primers for the PCR product were:

forward: 5'-GACCTTCTTATCCCGTCTCCA-3' and

reverse: 5'-CTAATACGACTCACTATAGGCTAAACCACAGTCACCAC AAA-3', where the underlined bases represent the T7 RNA polymerase promoter sequence.

\section{In situ hybridization}

Whole mount in situhybridization was performed with albino embryos as described in (Harland, 1991). One cell of 2-cell embryos was injected with $100 \mathrm{pg} z i c 1 \Delta C$ RNA, $100 \mathrm{pg}$ zic1 RNA, or 100 pg dnzic1 RNA together with $25 \mathrm{pg}$ lac $Z$ RNA as tracer. $\beta$-galactosidase staining was performed as in (Kolm and Sive, 1995). The alkaline phosphate substrate NBT/BCIP (Sigma) was used and for double in situ hybridizations, BCIP in combination with NBT/BCIP was used, although the color differences were lost during the second staining.

\section{$R T-P C R$}

RNA from pools of 14-25 animal cap explants or from 2 embryos was analyzed by RT-PCR as described (Kuo et al., 1998). The following primers were used: $N-C A M$ and $e n-2$ primers (Hemmati-Brivanlou and Melton, 1994), EF-1 $\alpha$ primers (Gammill and Sive, 1997), otx2 primers (Pannese et al., 1995), actin primers (Stutz and Spohr, 1986), wnt1 primers (forward: 5'-ATCGGGACTGTATTGCCAAG-3' reverse: 5'-ACCATTTGCCGCTGTTATTC-3') wnt3a primers (forward: 5'-CTGGGGAAGGCTGGAAGTG-3' reverse: 5'-TTGGGGGAGCTCTCATAGTAAATC-3') wnt4 primers (forward: 5'-GAGTCGCCTTTTCCCAGTCAT-3' reverse: 5'-GTAGCCCCATCAAATTTCTCCTTA-3') wnt5a primers (forward: 5'-CCCCGGGACTGGCTATGG-3' reverse: 5'-CGGGCTGGGGTCGATGTAAAC- 3') wnt5c primers (forward: 5'-CCGCGGAGAGGAGCAACAT-3' reverse: 5'-CACCCCGGCGGAACTGATAGC-3') $w n t 7 b$ primers (forward: 5'-ATGAAACTGGAGTGCAAATGTC-3' reverse: 5'-GCTGTCCTCCTCACAGTAGTTG-3') wnt8 primers (forward: 5'-AGATGACGGCATTCCAGA-3' reverse: 5'-TCTCCCGATATCTCAGGA-3') wnt8b primers (forward: 5'-CCGGACGAAAGGCAGTAAAGAG-3' reverse: 5'-TAACGGCTAAACCACAGTCACCAC-3') wnt11 primers (forward: 5'-CATTGCGCGTGCCTGTGC-3' reverse: 5'-GAGTGCCGGTCTGTCTGTGGATG-3').

\section{Acknowledgements}

We thank Robert VanTreese for help with the RT-PCR assays for Figure 3 and Kristin Junette for help with in situ hybridizations. We thank Randy Moon, Richard Harland, Doug Melton, Ali Hemmati-Brivanlou, Igor Dawid, Jan Christian and David Turner for kind gifts of plasmids. This work was supported by NIH grant 2RO1 HD33472 to H.L.S. and by NIHNRSA postdoctoralfellowship F32-HD-8495 andNSFgrant IOB-0417242 to C.S.M.

\section{References}

ARUGA, J. (2004). The role of zic genes in neural development. Mo/ Cel/ Neurosci 26: $205-21$.

BALLY-CUIF, L., ALVARADO-MALLART, R.M., DARNELL, D.K. and WASSEF, M (1992). Relationship between wnt-1 and en-2 expression domains during early development of normal and ectopic met-mesencephalon. Development 115 : 999-1009.

BENEDYK, M.J., MULLEN, J.R. and DINARDO, S. (1994). Odd-paired: A zinc finger pair-rule protein required for the timely activation of engrailed and wingless in Drosophila embryos. Genes Dev 8: 105-17.

BRIVANLOU, A.H. and HARLAND, R.M. (1989). Expression of an engrailed-related protein is induced in the anterior neural ectoderm of early Xenopus embryos. Development 106: 611-7.

CHANG, C. and HEMMATI-BRIVANLOU, A. (1998). Neural crest induction by Xwnt7b in Xenopus. Dev Bio/194: 129-34.

CHRISTIAN, J.L., MCMAHON, J.A., MCMAHON, A.P. and MOON, R.T. (1991). Xwnt-8, a Xenopus wnt-1/int-1-related gene responsive to mesoderm-inducing growth factors, may play a role in ventral mesodermal patterning during embryogenesis. Development 111: 1045-55.

CHRISTIAN, J.L. and MOON, R.T. (1993). Interactions between Xwnt-8 and Spemann organizer signaling pathways generate dorsoventral pattern in the embryonic mesoderm of Xenopus. Genes Dev7: 13-28.

CIANI, L. and SALINAS, P.C. (2005). Wnts in the vertebrate nervous system: From patterning to neuronal connectivity. Nat Rev Neurosci 6: 351-62.

CUI, Y., BROWN, J.D., MOON, R.T. and CHRISTIAN, J.L. (1995). Xwnt-8b: A maternally expressed Xenopus wnt gene with a potential role in establishing the dorsoventral axis. Development 121: 2177-86.

DANIELIAN, P.S. and MCMAHON, A.P. (1996). Engrailed-1 as a target of the wnt1 signalling pathway in vertebrate midbrain development. Nature 383: 332-4.

DINARDO, S. and O'FARRELL, P.H. (1987). Establishment and refinement of segmental pattern in the Drosophila embryo: Spatial control of engrailed expression by pair-rule genes. Genes Dev1: 1212-25.

DINARDO, S., SHER, E., HEEMSKERK-JONGENS, J., KASSIS, J.A. and O'FARRELL, P.H. (1988). Two-tiered regulation of spatially patterned engrailed gene expression during Drosophila embryogenesis. Nature 332: 604-9.

DOMINGOS, P.M., ITASAKI, N., JONES, C.M., MERCURIO, S., SARGENT, M.G., SMITH, J.C. and KRUMLAUF, R. (2001). The wnt/beta-catenin pathway posteriorizes neural tissue in Xenopus by an indirect mechanism requiring fgf signalling. Dev Bio/239: 148-60.

FREDIEU, J.R., CUI, Y., MAIER, D., DANILCHIK, M.V. and CHRISTIAN, J.L. (1997). Xwnt-8 and lithium can act upon either dorsal mesodermal or neurectodermal cells to cause a loss of forebrain in Xenopus embryos. Dev Biol 186: $100-14$

GAMMILL, L.S. and SIVE, H. (1997). Identification of otx2 target genes and restrictions in ectodermal competence during Xenopus cement gland formation. Development 124: 471-81.

GLAVIC, A., GOMEZ-SKARMETA, J.L. and MAYOR, R. (2002). The homeoprotein Xiro1 is required for midbrain-hindbrain boundary formation. Development 129: 1609-21.

HARLAND, R.M. (1991). In situ hybridization: An improved whole-mount method for Xenopus embryos. Methods Cell Bio/36: 685-95.

HE, X., SAINT-JEANNET, J.P., WOODGETT, J.R., VARMUS, H.E. and DAWID, 
I.B. (1995). Glycogen synthase kinase-3 and dorsoventral patterning in Xenopus embryos. Nature 374: 617-22.

HELLER, N. and BRANDLI, A.W. (1997). Xenopus pax-2 displays multiple splice forms during embryogenesis and pronephric kidney development. Mech Dev 69: 83-104.

HEMMATI-BRIVANLOU, A. and MELTON, D.A. (1994). Inhibition of activin receptor signaling promotes neuralization in Xenopus. Ce//77: 273-81.

HEMMATI-BRIVANLOU, A.H. and HARLAND, R.M. (1989). Expression of an engrailed-related protein is induced in the anterior neural ectoderm of early Xenopus embryos. Development 106: 611-7.

HOPPLER, S., BROWN, J.D. and MOON, R.T. (1996). Expression of a dominantnegative wnt blocks induction of MyoD in Xenopus embryos. Genes Dev 10: 2805-17.

HOWARD, K. and INGHAM, P. (1986). Regulatory interactions between the segmentation genes fushi tarazu, hairy and engrailed in the Drosophila blastoderm. Cel/44: 949-57.

INGHAM, P.W., BAKER, N.E. and MARTINEZ-ARIAS, A. (1988). Regulation of segment polarity genes in the Drosophila blastoderm by fushi tarazu and even skipped. Nature 331: 73-5.

KANIA, M.A., BONNER, A.S., DUFFY, J.B. and GERGEN, J.P. (1990). The Drosophila segmentation gene runt encodes a novel nuclear regulatory protein that is also expressed in the developing nervous system. Genes Dev 4: 170113.

KOLM, P.J. and SIVE, H.L. (1995). Regulation of the Xenopus labial homeodomain genes, hoxa1 and hoxd1: Activation by retinoids and peptide growth factors. Dev Bio/167: 34-49.

KRIEG, P.A. and MELTON, D.A. (1984). Functional messenger RNAs are produced by SP6 in vitro transcription of cloned cDNAs. Nucleic Acids Res 12: 7057-70.

KUO, J.S., PATEL, M., GAMSE, J., MERZDORF, C., LIU, X., APEKIN, V. and SIVE, H. (1998). Opl: A zinc finger protein that regulates neural determination and patterning in Xenopus. Development 125: 2867-82.

LAMB, T.M., KNECHT, A.K., SMITH, W.C., STACHEL, S.E., ECONOMIDES, A.N., STAHL, N., YANCOPOLOUS, G.D. and HARLAND, R.M. (1993). Neural induction by the secreted polypeptide noggin. Science 262: 713-8.

LI, S., SHIN, Y., CHO, K.W. and MERZDORF, C.S. (2006). The Xfeb gene is directly upregulated by zic1 in early neural development. Dev Dyn 235: (in press).

LOGAN, C.Y. and NUSSE, R. (2004). The wnt signaling pathway in development and disease. Annu Rev Cell Dev Bio/20: 781-810.

MARTINEZ ARIAS, A., BAKER, N.E. and INGHAM, P.W. (1988). Role of segment polarity genes in the definition and maintenance of cell states in the Drosophila embryo. Development 103: 157-70.

MCGREW, L.L., HOPPLER, S. and MOON, R.T. (1997). Wnt and fgf pathways cooperatively pattern anteroposterior neural ectoderm in Xenopus. Mech Dev 69: 105-14

MCGREW, L.L., LAI, C.J. and MOON, R.T. (1995). Specification of the anteroposterior neural axis through synergistic interaction of the wnt signaling cascade with noggin and follistatin. Dev Bio/172: 337-42.

MCGREW, L.L., OTTE, A.P. and MOON, R.T. (1992). Analysis of Xwnt-4 in embryos of Xenopus laevis: A wnt family member expressed in the brain and floor plate. Development 115: 463-73.

MCGREW, L.L., TAKEMARU, K., BATES, R. and MOON, R.T. (1999). Direct regulation of the Xenopus engrailed-2 promoter by the wnt signaling pathway and a molecular screen for wnt-responsive genes, confirm a role for wnt signaling during neural patterning in Xenopus. Mech Dev87: 21-32.

MCMAHON, A.P., JOYNER, A.L., BRADLEY, A. and MCMAHON, J.A. (1992). The midbrain-hindbrain phenotype of wnt-1-/wnt-1- mice results from stepwise deletion of engrailed-expressing cells by 9.5 days postcoitum. Cel/69: 581-95.

MIZUSEKI, K., KISHI, M., MATSUI, M., NAKANISHI, S. and SASAI, Y. (1998). Xenopus zic-related-1 and sox-2, two factors induced by chordin, have distinct activities in the initiation of neural induction. Development 125: 579-87.

MUNOZ-SANJUAN, I. and BRIVANLOU, A.H. (2002). Neural induction, the default model and embryonic stem cells. Nat Rev Neurosci3: 271-80.

NAKATA, K., KOYABU, Y., ARUGA, J. and MIKOSHIBA, K. (2000). A novel member of the Xenopus zic family, zic5, mediates neural crest development. Mech Dev 99: 83-91.

NAKATA, K., NAGAI, T., ARUGA, J. and MIKOSHIBA, K. (1997). Xenopus zic3, a primary regulator both in neural and neural crest development. Proc Nat/ Acad SCi USA 94: 11980-5.

NAKATA, K., NAGAI, T., ARUGA, J. and MIKOSHIBA, K. (1998). Xenopus zic family and its role in neural and neural crest development. Mech Dev75: 43-51.

NIEUWKOOP, P. and FABER, J. (1967). Normal table of Xenopus laevis (daudin) North-Holland Publishing Co, Amsterdam.

PANNESE, M., POLO, C. andREAZZOLI, M., VIGNALI, R., KABLAR, B. BARSACCHI, G. and BONCINELLI, E. (1995). The Xenopus homologue of otx2 is a maternal homeobox gene that demarcates and specifies anterior body regions. Development 121: 707-20.

SASAI, Y. and DE ROBERTIS, E.M. (1997). Ectodermal patterning in vertebrate embryos. Dev Bio/182: 5-20.

SIVE, H.L., HATTORI, K. and WEINTRAUB, H. (1989). Progressive determination during formation of the anteroposterior axis in Xenopus laevis. Cel/58: 171-80.

SMITH, W.C. and HARLAND, R.M. (1992). Expression cloning of noggin, a new dorsalizing factor localized to the Spemann organizer in Xenopus embryos. Cell 70: 829-40.

SONG, D.L., CHALEPAKIS, G., GRUSS, P. and JOYNER, A.L. (1996). Two paxbinding sites are required for early embryonic brain expression of an engrailed2 transgene. Development 122: 627-35.

STUTZ, F. and SPOHR, G. (1986). Isolation and characterization of sarcomeric actin genes expressed in Xenopus laevis embryos. J Mol Biol187: 349-61.

SUGIYAMA, S., FUNAHASHI, J., KITAJEWSKI, J. and NAKAMURA, H. (1998). Crossregulation between en-2 and wnt-1 in chick tectal development. Dev Growth Differ 40: 157-66.

SWANTEK, D. and GERGEN, J.P. (2004). Ftz modulates runt-dependent activation and repression of segment-polarity gene transcription. Development131:228190.

TROPEPE, V., LI, S., DICKINSON, A., GAMSE, J.T. and SIVE, H.L. (2006). Identification of a BMP inhibitor-responsive promoter module required for expression of the early neural gene zic1. Dev Bio/289: 517-29.

TURNER, D.L. and WEINTRAUB, H. (1994). Expression of achaete-scute homolog 3 in Xenopus embryos converts ectodermal cells to a neural fate. Genes Dev 8 1434-47.

UMBHAUER, M., PENZO-MENDEZ, A., CLAVILIER, L., BOUCAUT, J. and RIOU, J. (2000). Signaling specificities of fibroblast growth factor receptors in early Xenopus embryo. J Cel/ Sci113 (Pt 16): 2865-75.

WANG, J. and WYNSHAW-BORIS, A. (2004). The canonical wnt pathway in early mammalian embryogenesis and stem cell maintenance/differentiation. Curr Opin Genet Dev 14: 533-9.

WODARZ, A. and NUSSE, R. (1998). Mechanisms of wnt signaling in development. Annu Rev Cell Dev Biol 14: 59-88.

WOLDA, S.L., MOODY, C.J. and MOON, R.T. (1993). Overlapping expression of Xwnt-3a and Xwnt-1 in neural tissue of Xenopus laevis embryos. Dev Bio/155: 46-57.

Received: October 2005

Reviewed by Referees: November 2005 Modified by Authors and Accepted for Publication: May 2006 Published Online: August 2006 Edited by: Edward M. De Robertis 